\title{
Causes of Maternal Mortality in 2020 in the Kara Region (Togo)
}

\author{
Dédé Régine Diane Ajavon ${ }^{*}$, Logbo-Akey Kossi Edem1 ${ }^{1}$, Kambote Yendoube', Agoro Sibabe², \\ Ali Hélène ${ }^{2}$, Beley Christine ${ }^{3}$, Aledi Tchilalo ${ }^{3}$, Sodou Pouzouwè ${ }^{3}$, Gnakou Louise ${ }^{3}$, \\ Aboubakari Abdoul Samadou' ${ }^{1}$
}

${ }^{1}$ Department of Obstetric Gynecology, University of Kara, Kara, Togo

${ }^{2}$ Kara Regional Health Directorate, Kara, Togo

${ }^{3}$ National School of Midwives of Kara, Kara, Togo

Email: *ddajavon@yahoo.fr

How to cite this paper: Ajavon, D.R.D., Edem, L.-A.K., Yendoube, K., Sibabe, A., Hélène, A., Christine, B., Tchilalo, A., Pouzouwè, S., Louise, G. and Samadou, A.A. (2022) Causes of Maternal Mortality in 2020 in the Kara Region (Togo). Open Journal of Obstetrics and Gynecology, 12, 104-111. https://doi.org/10.4236/ojog.2022.121010

Received: December 16, 2021

Accepted: January 24, 2022

Published: January 27, 2022

Copyright $\odot 2022$ by author(s) and Scientific Research Publishing Inc. This work is licensed under the Creative Commons Attribution International License (CC BY 4.0).

http://creativecommons.org/licenses/by/4.0/

(c) (i) Open Access

\begin{abstract}
Objective: Determine the maternal mortality rate, the epidemiological profile, the causes of death and the dysfunctions noted. Patients and method: This was a cross-sectional and descriptive study from January 1 to December 31, 2020. All maternal deaths during pregnancy or within 42 days after its termination fitting the World Health Organisation definition criteria that occurred in the seven districts of Kara region were included. The data were processed using Excel microsoft. Results: A total of 41 maternal deaths occurred among 23,456 live births, accounting for a maternal mortality ratio of 174.8 deaths per 100,000 live births. The followings were observed: the average age of 30 years; $88 \%$ married; $39 \%$ multiparous; $78 \%$ housewives without income; $5 \%$ students. Hemorrhage, preeclampsia, and complications of abortion were the main direct obstetric causes, while anemia was the main indirect obstetric cause. Factors related to deaths were inadequate quality of health care and lack of universal health insurance. The various maternal death audit reports found that $94.4 \%$ of deaths were preventable. Conclusion: Most maternal deaths would be prevented in the Kara region if women during pregnancy and the postpartum period received quality health care and the community was involved in decision-making about their health.
\end{abstract}

\section{Keywords}

Maternal Deaths, Audit, Causes, Preventable

\section{Introduction}

Maternal mortality is defined as deaths occurring in women, while pregnant or within the 42 days of termination of pregnancy irrespective of the duration and 
site of the pregnancy, from any cause related to or aggravated by the pregnancy or its management, but not from accidental or incidental causes according to the World Health Organization [1]. The main causes are severe bleeding, infections, pre-eclampsia and eclampsia, complications from delivery and unsafe abortion. In sub-Saharan Africa, the lifetime risk of a woman dying from pregnancy or childbirth is 1 in 39 compared to 1 in 4700 in developed countries. In Togo, it was 401 deaths per 100,000 live births in 2017 [1] [2] [3]. These deaths are "mostly preventable", because the necessary medical interventions exist and are well known. However, the main barriers are lack of access to care and poor quality of care provided to women in hospitals during pregnancy, delivery, and the early postpartum period [1] [2]. In order to reduce these obstacles, several national strategies have been put in place to subsidize obstetric care [4]. For targeted and direct action, Maternal Death Surveillance and Response (MDSR) is organized in each health region. MDSR is a form of continuous surveillance that bridges the health information system and quality of care improvement processes from the local to the national level [1] [5]. Despite the response put in place in the Kara region having initiated a decline in the maternal mortality rate, it has recorded an increase in 2020. Indeed, the annual reviews of health activities in the Kara region showed that this rate, which was 130.7 deaths per 100,000 live births in 2018 and 129.4 deaths per 100,000 live births in 2019, increased significantly in 2020 with the Covid 19 pandemic [6].

The objective of this study was to determine the epidemiological profile and identify causes and determinants of maternal deaths.

\section{Patients and Method}

This was a cross-sectional and descriptive study from January 1 to December 31, 2020. All maternal deaths during pregnancy or within 42 days after its termination fitting the World Health Organisation definition criteria that occurred in the seven districts of Kara region were included in the study.

Data source: records of deceased patients, notification forms, audit forms, and monthly activity reports from maternity services in the seven health districts.

The data were processed using Excel microsoft.

\section{Results}

\subsection{Epidemiological Profile}

\subsubsection{Maternal Mortality Rate}

The Kara region recorded 41 maternal deaths among 23,456 live births in health facilities in 2020. The hospital maternal mortality rate was 174.8 deaths per 100,000 live births.

\subsubsection{Socio-Demographic Characteristics}

The average age was 30 years with extremes of 13 and 48 years. The majority were married ( 36 cases; $87.8 \%$ ) and in 5 cases (12.2\%) single. Regarding parity, they were multiparous (16 cases; $39 \%$ ), pauciparous (15 cases; $36.6 \%$ ), primi- 
parous (5 cases; $12.2 \%$ ) and nulliparous (5 cases; $12.2 \%$ ). They had a low socio-economic level. They were housewives (32 cases; 78\%), sellers (6 cases; $14.7 \%$ ), students ( 2 cases; $4.9 \%$ ) and seamstresses ( 1 case; $2.4 \%$ ). Table 1 summarizes the distribution by age group.

\subsubsection{Antenatal Care}

Twenty-two $(53.7 \%)$ of the deceased patients did not attend the antenatal care and $19(46.3 \%)$ did.

\subsubsection{Circumstances of Maternal Deaths}

Thirty-five (85.4\%) died in health facilities offering complete emergency obstetric and neonatal care, while $06(14.6 \%)$ died in health facilities offering basic emergency obstetric and neonatal care and peripheral care units. Among the women who delivered, 9 deaths occurred in the post-caesarean period. We have summarized the distribution of deaths by time period in Table 2.

Thirty-five patients $(85.4 \%)$ died within 24 hours of admission to the referral center. The distribution according to the length of stay is summarized in Figure 1.

\subsection{Causes of Maternal Death}

Direct obstetrical causes represented 28 cases or $68.3 \%$ while indirect obstetrical causes represented 13 cases or $31.7 \%$.

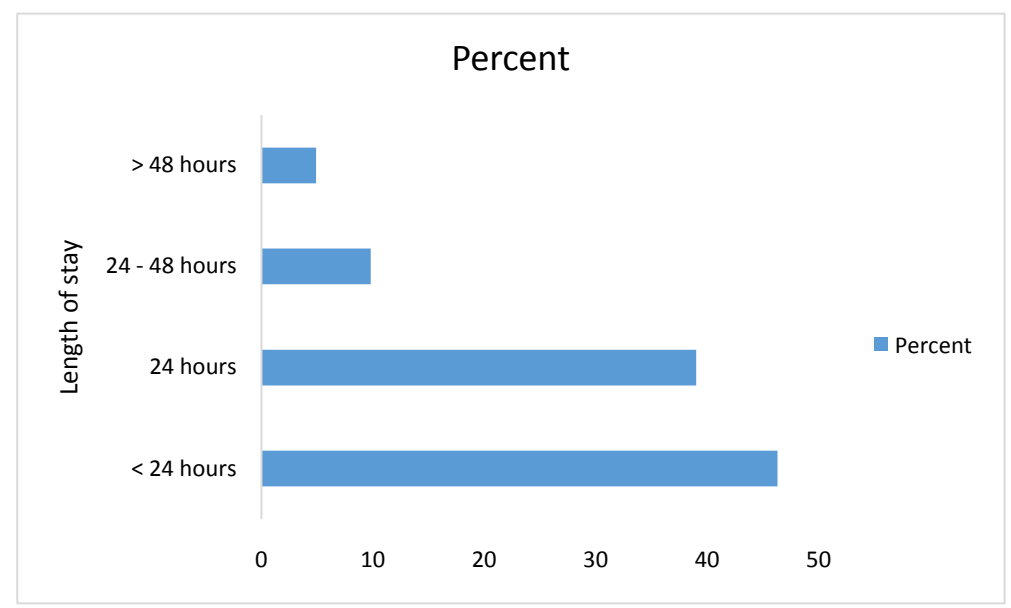

Figure 1. Distribution of patients according the length of stay before death.

Table 1. Distribution of maternal deaths by age group.

\begin{tabular}{ccc}
\hline & Effectif & Per cent \\
\hline$<15$ ans & 1 & 2.4 \\
{$[15-24$ ans $]$} & 8 & 19.5 \\
{$[25-34$ ans $]$} & 19 & 46.4 \\
{$[35-44$ ans $]$} & 12 & 29.3 \\
$\geq 45$ ans & 1 & 2.4 \\
Total & 41 & 100.0 \\
\hline
\end{tabular}


Table 2. Distribution of deaths by time period.

\begin{tabular}{ccc}
\hline & Effectif & Per cent \\
\hline Postpartum & 19 & 46.3 \\
Pregnancy & 17 & 41.5 \\
Post abortum & 4 & 9.8 \\
Per partum & 1 & 2.4 \\
Total & 41 & 100 \\
\hline
\end{tabular}

\subsubsection{Direct Obstetrical Causes}

Obstetric hemorrhages (ante and per partum hemorrhage ( 7 cases) and immediate post-partum hemorrhage (6 cases)) were the main causes of maternal death. Figure 2 summarizes the distribution of patients who died according to direct obstetric causes.

\subsubsection{Indirect Obstetrical Causes}

Anemia was the main indirect cause ( 9 cases; 69.2\%), followed by sickle cell disease ( 2 cases; 15.4\%), amniotic embolism and anesthetic complication during cesarean section ( 2 cases; $15.4 \%)$.

\subsection{Monitoring of Maternal Deaths}

The monitoring of maternal deaths in the Kara region allowed for the recording of deaths that occurred in the health facilities. Of the 41 deaths recorded, all were notified, i.e., a rate of $100 \%$. However, 36 were audited (87.8\%) and 5 were not audited (12.2\%). During these audits, $94.4 \%$ (34 cases out of 36 ) were considered preventable. The amniotic embolism and the anaesthetic complication were judged as not preventable. In cases where deficiencies were found, the death was deemed preventable and the elements and factors that could be acted upon to prevent it were identified and recommendations made.

\subsubsection{Elements of Health Care Related to Deaths}

Conditions of admission: Twenty-three patients (56.1\%) were referred, eight (19.5\%) were evacuated and $10(24.4 \%)$ were self-referred. No patient had received medical transport and did not receive care during evacuation. Among the 31 patients referred/evacuated, 11 deceased patients (35.5\%) were admitted without a referral form but the center was informed by telephone call in 5 cases. However, 20 deceased patients (64.5\%) arrived with a referral form. Table 3 summarizes the distribution according to the means of transport.

Management of Care: In 12 cases, there was a delay in referral/evacuation, but all 31 patients referred/evacuated had received a venous approach. In 11 cases, management was considered inadequate in terms of diagnosis, treatment, and follow-up. Lack of antenatal care and poor quality pregnancy follow-up (26 cases) have been incriminated. 




Figure 2. Distribution of direct causes of maternal death.

Table 3. Distribution according to the means of transport.

\begin{tabular}{ccc}
\hline & Effectif & Per cent \\
\hline Taxi & 20 & 48.8 \\
Motorcycle Taxi & 13 & 31.7 \\
Tricycles & 05 & 12.2 \\
Ambulance & 03 & 7.3 \\
Total & 41 & 100 \\
\hline
\end{tabular}

\subsubsection{Factors Related to Deaths}

Factors related to management failures were lack of emergency blood products ( 3 cases), lack of equipment ( 7 cases), lack of qualified personnel (3 cases), poor organization of services (6 cases), delay in consultation and referral (29 cases), lack of universal health insurance (lack of financial means in all cases).

\section{Discussion}

As the year 2020 was marked by the pandemic in Covid-19, the Kara region experienced a decline in reproductive health activities in general and a particular increase in home deliveries [6]. The maternal mortality ratio was 174.8 deaths per 100,000 live births in 2020. A 2006 study by Aboubakari [7] at the Kara University Hospital found a rate of 3600 deaths per 100,000 live births. However, this rate has decreased over the years thanks to various strategies within the framework of safe motherhood. However, the policies and reforms instituted within the framework of maternal health are not always implemented in the health care facilities [4].

The postpartum period was the period of greatest risk. In most cases, they died within the first 24 hours after admission. Low socioeconomic status, multi- 
parity and pauciparity, poor transfer conditions, and delay in access to care may have contributed to these deaths. Factors associated with maternal deaths were: delay of evacuation, delay to support decision making, delay to medical consultation, poor care management according to studies carried out in Burkina Faso by Ouedraogo [8], in Chad by Foumsou [9] and in Benin by Atade [10].

Maternel deaths are subdivised into two groups, direct and indirect obstetric deaths. The direct obstetric death are those resulting from obstetric complications of the pregnancy state (pregnancy, labour and the puerperium) from interventions, omissions, incorrect treatment, or from a chain of events resulting from any of the above. The indirect obstetric deaths are those resulting from previous existing disease or disease that developed during pregnancy and which was not due to direct obstetric causes, but which was aggravated by physiologic effects of pregnancy [1]. The main obstetric causes were hemorrhage (45\%), pre-eclampsia and complications (31\%), complications of abortion (10\%). Hemorrhage remains the first maternal cause especially in low-income countries due to insufficient preventive measures, insufficient use of care protocols [7]-[12].

Eclampsia would be the first complication of pre-eclampsia which can be prevented by parenteral administration of magnesium sulfate [13]. The occurrence of death due to complications of pre-eclampsia would be favored by the absence of antenatal care or poor quality follow-up. In most countries in Africa, including Togo, the law on abortion is restrictive. This restriction promotes clandestine and illegal abortions. Post abortion peritonitis and pelviperitonitis are frequent complications of clandestine abortions. These complications were responsible for $14.29 \%$ of deaths according to Bassowa study in Lomé, Togo [14]. Complications of abortions are recurrent.

Indirect obstetric causes were dominated by anemia (76.92\%), followed by sickle cell disease (15.38\%). Anemia is caused by a lack of iron in the woman's diet or poor absorption of iron from food, malaria and other parasitic infections [15].

The causes of maternal deaths have been known for a long time and various strategies have not been sufficient to significantly reduce them. The search for root causes could address this issue. Thus, verbal autopsy has a considerable contribution to make in measuring maternal mortality, especially in rural areas where the causes of death are generally ignored [16].

Regarding admission conditions: evacuations were not medicalized, evacuations were late, no referral forms were available, and consultations were late. The quality of care provided to women is a key determinant of pregnancy outcome and simply changing practices can save many lives [1] [2]. These different factors were not present in the management of these patients. Thus, the unavailability of equipment and blood products in emergency was noted. Also, the diagnosis was inadequate due to the lack of emergency diagnostic means and qualified personnel. The treatment depends on the diagnosis and the financial means of the families. Follow-up did not comply with standards. These different dysfunctions led to a non-optimal care of the patients. 
Obstetrical emergencies require multidisciplinary management. The organization of services, intra- and inter-hospital communication and community awareness remain challenges for the maternity services that manage these emergencies. A well-coded protocol and the effective implementation of preventive measures would be the best alternative to reduce these preventable maternal deaths.

Death audits revealed that $94.4 \%$ of deaths were preventable. The goal of maternal death surveillance and response is to eliminate preventable maternal mortality by obtaining and using information strategically to guide public health actions and evaluate their impact [2]. The role of the multidisciplinary audit committee is to ensure that lessons learned are acted upon [5]. These deaths could be prevented in the Kara region when the audit recommendations are implemented. Maternal health is closely linked to women's social and economic status. Investing in their education and empowerment is essential to prevent maternal deaths [17]. More than four-fifths of the deceased women in our study had a low socioeconomic level. New obstetrical care subsidy program launched in 2021 by the Department of Health could relieve financial difficulties for women and their families. Also, the improvement of the referral system for pregnant women, parturients, and deliveries, the respect of care protocols, and supervision are indispensable for quality obstetrical care. Audits of obstetrical complications would be necessary to demonstrate good practices.

\section{Conclusion}

Maternal mortality remains high in the Kara region, yet the majority of deaths are preventable. Several dysfunctions have been identified in the management of maternal mortality. The causes and factors related to the lack of quality care are known. Several actions are implemented. The response component of the Maternal Death Surveillance and Response needs to be enhanced to ensure synergy of actions.

\section{Conflicts of Interest}

The authors declare no conflicts of interest regarding the publication of this paper.

\section{References}

[1] World Health Organization (2015) Maternal Death Surveillance and Response: Guidelines and Techniques: Preventing Maternal Deaths, Information for Action. WHO Library, Geneva. https://www.who.int/iris/handle/10665/194270

[2] World Health Organization (2004) Beyond the Numbers: Examining Maternal Deaths and Complications to Reduce Pregnancy-Related Risks. WHO, Geneva.

[3] Ministry of Health and Social Protection. (2017) National Health Development Plan 2017 -2022. Republic of Togo, p. 11.

[4] Mitronougna, K.K. (2020) Public Health Policies and Reduction of Maternal Mortality: The Daily Reality in the Para-Public Health Centers in Togo. Revue Espace, Territoires, Sociétés et Santé, 3, 65-82. 
[5] Traoré, S.O., Samaké, A., Doumbia, S., Sangaré, R.T., Kouyaté, F.I., Traoré, M.A., Traoré, O.M., Téguété, I., Traoré, Y., Mounkoro, N., Traoré, M. and Akotionga, M. (2019) Conduct of a Maternal Death Review Session: A Literature Review. Health Sciences and Disease, 20, 112-117

[6] Kara Regional Health Directorate (2018-2020) Annual Reviews of Health Activities in the Kara Region from 2018 to 2020. Ministry of Health, Public Hygiene and Universal Access to Universal Care, Togo.

[7] Aboubakari, A.S., Agbettra, N., Adama, H. and Akpadza, K. (2006) Maternal Mortality at Kara Hospital: Incidence, Causes and Risk Factors. Journal SAGO, 7, 5-10.

[8] Ouedraogo, I., Sib, S.R., Kiemtore, S., Sawadogo, Y., Kain, D.P., Zamané, H., Ouattara, A., Goumbri, A., Kabore, S.Y., Ouedraogo, A. and Bonané-Thiéba, B. (2017) Maternal Mortality in the Obstetrics and Gynecology Service of Regional Hospital Center of Ouahigouya: Epidemiological, Etiological Aspects and Contributing Factors-About 151 Cases Collected in Three Years from 1st January 2013 to December 2015. Open Journal of Obstetrics and Gynecology, 7, 447-454. https://doi.org/10.4236/ojog.2017.74046

[9] Foumsou, L., Saleh, A., Kaimba, O., Djongali, S., Djimté, N. and Mignagnal, K. (2010) Determinants of Maternal Mortality at N'Djamena General and National Reference Hospital-Tchad. Dissemination and Valorisation of the Results of Scientific and Technical Research of the CNAR, 1-7.

[10] Atade, S.R., Hounkponou Ahouingnan, F.M.N., Obossou, A.A.A., Gabkika, B.M., Doha, S.M.I., Sidi, R.I., Vodouhè, M.V. and Salifou, K. (2021) Factors Associated with Maternal Deaths at Saint John of God Zonal Hospital in Tanguieta from 2015 to 2019. European Scientific Journal, 17, 93-105.

[11] Mbeva Kahindo, J.B., Karemere, H., Mitangala, N.P., Nyavanda, L. and W'itende, M.J.P. (2018) Maternal Deaths Factors in Hospital Area: A Survey at Six Health Districts in the East of the Republic Democratique of Congo. International Journal of Innovation and Applied Studies, 23, 559-568.

[12] Sawadogo, Y.A., Zamané, H., Kiemtoré, S., Sib, S.R., Kain, D.P., Ouédraogo, I., Ouattara, A., Ouédraogo, C. and Ouédraogo, A. (2019) Maternal Morbidity by Direct Obstetric Causes in an Urban Referral Hospital: Case of Boulmiougou District Hospital in Ouagadougou, Burkina Faso. International Journal of Reproduction, Contraception, Obstetrics and Gynecology, 8, 3009-3014. https://doi.org/10.18203/2320-1770.ijrcog20193511

[13] Kampo, M.I., Sogoba, S. and Dembélé, K. (2020) Maternal and Perinatal Prognosis of Eclampsia at the Timbuktu Hospital in Mali. Pan African Medical Journal, 36, 175. https://doi.org/10.11604/pamj.2020.36.175.17976

[14] Akila, B., Ayoko, K., Déde, A., Douaguibebaguilane, Kodjo, F., Samadou, A. and Koffi, A. (2018) Peritonis and Pelviritonis Following Clandestinal Abortion Received at Sylvanus Olympio Teaching Hospital of Lomé. International Annals of Medicine, 2, No. 10. https://doi.org/10.24087/IAM.2018.2.10.643

[15] Population Reference Bureau (2003) Maternal Mortality a Leading Cause of Death in Cambodia. Washington DC.

[16] Ba, M.G., Belco, K. and Jean-François, E. (2003) Verbal Autopsy to Measure Maternal Mortality in Rural Senegal. Journal of Gynecology Obstetrics and Reproductive Biology, 32, 728-735.

[17] UNFPA (2012) Rich Mother, Poor Mothers: The Social Determinants of Maternal Death and Disability. Updated with Technical Feedback from December 2012, 7 p. https://www.unfpa.org 